INTERNACIONAL

\title{
Mujeres, protestas sociales y represión estatal en Argentina, Chile y México
}

Women, social protests, and State repression in Argentina, Chile, and Mexico

\author{
Mariana Brocca (iD y Camila Agustina Ormar (iD
}

Universidad Nacional del Centro de la Provincia de Buenos Aires, Argentina

\begin{abstract}
RESUMEN El presente trabajo tiene por propósito estudiar las razones de la represión de índole sexual que se ejerce contra las mujeres en el marco de las protestas sociales. Así, teniendo en cuenta los estándares interamericanos relativos al derecho a participar en manifestaciones pacíficas, el artículo analizará casos específicos de represión de países de la región (Argentina, Chile y México), para luego ahondar cuáles han sido las explicaciones que se han dado desde la literatura académica a estos fenómenos.
\end{abstract}

PALABRAS CLAVE Protestas sociales, represión, violencia sexual, género, América Latina.

\begin{abstract}
This paper has the aim of studying the reasons behind the repression against women during social protests. It will focus specially on the sexual violence that women suffer in those circumstances. Thus, starting from the Inter-American standard on the matter, the article will analyze specific repression cases of the region (Argentina, Chile, and Mexico). Then, it will delve into the explanations that academia has given to these phenomena.
\end{abstract}

KEYWORDS Social protests, repression, sexual violence, gender, Latin America.

\section{Introducción}

En América Latina, los términos represión y protesta social suelen ir acompañados. Basta con recorrer la historia de los países de la región para confirmar que la violencia institucional en el marco de las manifestaciones es moneda corriente (CELS, 2016: Waldmann, 1995). En los últimos años, esta respuesta estatal ha estado en gran parte 
dirigida a las movilizaciones lideradas por mujeres que buscan reivindicar sus derechos (CELS, 2016). Ello se debe, en suma, al alza de protestas feministas impulsadas en la región durante la última década. Así, luego de una historia cargada de discriminación y violencia, las mujeres han ido adueñándose de los ámbitos públicos con el objetivo de visibilizar su realidad y reclamar por cuestiones esenciales, como lo es una tener vida libre de violencia.

De acuerdo con Combes y Fillieule (2011), en el marco de la sociología existen numerosos trabajos que abordan la conexión entre las protestas sociales y la represión. Si bien esta literatura ha expuesto diversos factores que pretenden explicar la relación entre estos fenómenos, hay dos con los que, en general, se ha llegado a un consenso: i) las protestas generan un incremento en la represión; y ii) el uso pasado de la represión aumenta las posibilidades de que sea utilizada nuevamente. Así, puede observarse que ambos fenómenos se encuentran estrechamente ligados, por lo que es necesario su estudio en conjunto.

Ahora bien, para poder adentrarnos en la temática, debemos comenzar por preguntarnos qué entendemos por protesta y por represión. En cuanto al primer término, la Comisión Interamericana de Derechos Humanos (CIDH, 2019: 5) lo define como «una forma de acción individual o colectiva dirigida a expresar ideas, visiones o valores de disenso, oposición, denuncia o reivindicación». Por su parte, la literatura académica en general define a la represión como una política que amenaza o hace uso de la violencia con el propósito de remover o amedrentar a un grupo de gente - ya sea numeroso o reducido- cuando este desafía las estructuras de poder o sus políticas fundamentales (Henderson, 2004: 1.031). No obstante, distintas autoras han observado que esta noción generalizada carece de un enfoque de género. Ello se advierte, sobre todo, si se tienen en cuenta las formas específicas de violencia que sufren las mujeres ante la represión estatal (que tampoco suelen ser estudiadas). Podría decirse, entonces, que con una primera aproximación ya queda expuesta la falsa neutralidad con la que se pretende analizar este fenómeno social, la cual genera una invisibilización de las realidades diferenciadas que viven las mujeres.

Tomando esta realidad como punto de partida, el objetivo de este artículo es analizar la relación entre las manifestaciones sociales y la represión contra las mujeres en el ámbito latinoamericano. Para lograr este objetivo, el trabajo considerará tres casos en particular: los de Argentina, Chile y México. Si bien se reconoce que las movilizaciones se han reproducido y masificado en toda la región, se analizarán dichos países dada la resonancia que han tenido en los distintos medios las manifestaciones de mujeres reprimidas por agentes estatales allí ocurridas. Así las cosas, el artículo estudiará estos casos a la luz de los estándares interamericanos y, sobre todo, del avance jurisprudencial en el sistema interamericano de derechos humanos. Además, se tendrán en cuenta investigaciones académicas que han procurado exponer la represión contra las mujeres en el marco de la vida política y, en particular, de las protestas sociales. 
Con base en ello, el presente trabajo se dividirá en cuatro partes. La primera introducirá los estándares interamericanos en la materia y las obligaciones estatales que surgen de este contexto. En el segundo apartado se hará referencia a la oleada de protestas sociales lideradas por mujeres en Argentina, Chile y México y su respuesta estatal. En la tercera parte, este artículo abordará las razones que se encuentran detrás de la represión y las formas de violencia específicas perpetradas contra las mujeres. De este modo, luego de hacer un análisis sobre conceptos clave - como los de contrato sexual y división sexual del trabajo-, se tendrán en cuenta ciertas investigaciones desarrolladas por la academia que echan luz sobre el tema. Finalmente, el último apartado presentará las conclusiones a las que se hayan arribado.

\section{Estándares interamericanos}

\section{Protestas sociales y abuso de la fuerza estatal}

En el marco del sistema interamericano de derechos humanos, el derecho a la protesta social ha sido abordado en diversas ocasiones. A modo de ejemplo, en su reciente y resonado caso Mujeres de Atenco con México, la Corte Interamericana de Derechos Humanos (Corte IDH) se pronunció sobre el derecho a manifestarse a la luz de la Convención Americana sobre Derechos Humanos (CADH) y la represión estatal. Los hechos del caso hacen referencia a un grupo de mujeres detenidas por agentes estatales durante una protesta social, sometiéndolas luego a distintos tipos de violencia sexual. En este marco, la Corte IDH afirmó en su sentencia que «la posibilidad de manifestarse pública y pacíficamente es una de las maneras más accesibles de ejercer el derecho a la libertad de expresión, por medio de la cual se puede reclamar la protección de otros derechos». ${ }^{1}$ Con base en ello, el tribunal interamericano estableció que este derecho es de carácter fundamental para una sociedad democrática, por lo que su alcance no debe interpretarse de forma restrictiva.

En el mismo sentido se ha pronunciado la CIDH. En el informe de 2019 sobre Protestas sociales y derechos humanos, la Comisión advirtió que el derecho a participar en manifestaciones y protestas incluye, al menos, otros cuatro: i) derecho a participar en protesta sin autorización previa; ii) derecho a elegir el contenido y mensajes de la protesta; iii) derecho a escoger el tiempo y lugar de la protesta; iv) derecho a escoger el modo de protesta (CIDH, 2019: 28-35). De esta forma, los Estados tienen la obligación de proteger el derecho a participar en manifestaciones de modo que estos otros derechos también se vean garantizados.

Para lograr un pleno ejercicio del derecho en cuestión, el uso de la fuerza debe ser

1. Sentencia del caso Mujeres Víctimas de Tortura Sexual en Atenco con México, Corte Interamericana de Derechos Humanos, serie C núm. 371, excepción preliminar, fondo, reparaciones y costas, 28 de noviembre de 2018, foja 171. 
de carácter excepcional. Al respecto, en Mujeres de Atenco, la Corte IDH manifestó que, si bien los Estados tienen el derecho a hacer uso legítimo de la fuerza para garantizar la seguridad y orden públicos del territorio bajo su jurisdicción, este poder no es ilimitado. En esta misma línea, la CIDH ha explicado que «el recurso de la fuerza pública puede constituir un elemento importante para garantizar el derecho a la protesta y proteger la integridad de los manifestantes. Por otro lado, también representa una importante fuente de violaciones a estos mismos derechos». ${ }^{2}$ De este modo, para que pueda hacerse uso de la fuerza, deben presentarse indiscutiblemente los siguientes elementos:

- Legalidad: Este principio hace referencia a la sanción de normas que posean jerarquía de ley (CIDH, 2019: 42).

- Absoluta necesidad: Es decir, que el uso de la fuerza debe limitarse a «medidas de seguridad ofensivas y defensivas estrictamente necesarias para el cumplimiento de las órdenes legítimas impartidas por la autoridad competente ante hechos violentos o delictivos que pongan en riesgo el derecho a la vida o a la integridad personal de cualquier habitante» (CIDH, 2019: 42).

- Proporcionalidad: La CIDH la ha entendido como «la moderación en el actuar de los agentes del orden que procurará minimizar los daños y lesiones que pudieren resultar de su intervención» (CIDH, 2019: 43).

Sumado a ello, los Estados deben prestar especial protección a las protestas desarrolladas por ciertos grupos históricamente discriminados, como lo son las mujeres. Siguiendo el estándar planteado por el relator especial sobre los derechos a la libertad de reunión pacífica y de asociación de Naciones Unidas, la CIDH ha señalado que «en el caso de restringirse o excluirse el ejercicio de los derechos de libertad de reunión y asociación de estos grupos, se reforzará su marginación» (CIDH, 2019: 23).

Así las cosas, se observa que los Estados deben adoptar las medidas que sean necesarias para que las personas puedan manifestarse libremente, pudiendo hacer uso de la fuerza solo como medida de ultima ratio. Además, si las personas que buscan manifestarse pertenecen a un grupo discriminado estructuralmente, debe procurarse una especial protección a su derecho a la protesta pacífica. En otras palabras, la posibilidad de limitar el ejercicio de este derecho se ve aún más restringida.

\section{Violencia sexual por parte de agentes estatales}

En consonancia con lo expuesto arriba, la Corte IDH ha desarrollado una vasta jurisprudencia en materia de violencia sexual contra mujeres por parte de agentes estata-

2. Sentencia del caso Mujeres Víctimas de Tortura Sexual en Atenco con México, foja 41 (el destacado es nuestro). 
les. En un comienzo, el tribunal partió con una interpretación por demás restrictiva; en efecto, en el caso Loayza Tamayo con Perú (relativo a actos de tortura por parte de agentes estatales en la época de Fujimori), si bien la peticionaria declaró que había sido víctima de violencia sexual por los funcionarios que la mantenían privada de su libertad, el tribunal no analizó dicha violación por supuesta falta de pruebas. ${ }^{3}$ Así, de acuerdo con la Corte IDH, a pesar de que en la demanda se especificaba que la víctima había sido violada, manifestó que, debido a la naturaleza del hecho, no podía darlo por probado.

No obstante, con el paso de los años - y la lenta pero cierta incorporación de mujeres feministas al tribunal- la Corte IDH fue cambiando su interpretación, aplicando tanto la CADH como la Convención Belém do Pará a los casos de violencia sexual contra mujeres. El primer paso lo dio en el leading case de Penal Miguel Castro Castro con Perú, en que responsabilizó al Estado peruano por la violencia sexual sufrida por las mujeres víctimas del «Operativo Mudanza 1». Allí, el tribunal estableció que «la violencia sexual se configura con acciones de naturaleza sexual que se cometen en una persona sin su consentimiento, que además de comprender la invasión física del cuerpo humano, pueden incluir actos que no involucren penetración o incluso contacto físico alguno». ${ }^{4}$

Respecto a la prueba, la Corte modificó rotundamente el estándar planteado en Loayza Tamayo. En efecto, en el caso Espinoza Gonzáles con Perú aclaró que «las agresiones sexuales se caracterizan, en general, por producirse en ausencia de otras personas más allá de la víctima y el agresor o los agresores» y que «dada la naturaleza de estas formas de violencia, no se puede esperar la existencia de pruebas gráficas o documentales y, por ello, la declaración de la víctima constituye una prueba fundamental sobre el hecho».5 Así las cosas, si bien la naturaleza del hecho fue la razón por la cual el tribunal no analizó la alegada violación sexual en Loayza Tamayo, con el quiebre jurisprudencial generado a partir de Castro Castro se constituyó en el motivo principal por el que el testimonio de la víctima recobró relevancia.

En esta misma línea de pensamiento, la Corte IDH ha determinado que, al estudiar las declaraciones de las víctimas en materia de violencia sexual, se debe tener en consideración que este tipo de crímenes suelen generar estigma social; debido a ello, muchas mujeres no suelen denunciarlos. ${ }^{6}$ Además, al ser hechos traumáticos,

3. Sentencia del caso Loayza Tamayo con Perú, Corte Interamericana de Derechos Humanos, serie C núm. 33, fondo, 17 de septiembre de 1997.

4. Sentencia del caso Penal Miguel Castro Castro con Perú, Corte Interamericana de Derechos Humanos, serie $\mathrm{C}$ núm. 160, fondo, reparaciones y costas, 25 de noviembre de 2006, foja 306.

5. Sentencia del caso Espinoza Gonzáles con Perú, Corte Interamericana de Derechos Humanos, serie C núm. 295, excepciones preliminares, fondo, reparaciones y costas, 20 de noviembre de 2014, foja 150.

6. Sentencia del caso Espinoza Gonzáles con Perú. 
los relatos pueden presentar imprecisiones, pero estas no implican de modo alguno falsedad. A esto se suma que no es necesario que se presente evidencia médica para que un testimonio sea considerado verdadero: «En tales casos, no necesariamente se verá reflejada la ocurrencia de violencia o violación sexual en un examen médico, ya que no todos los casos de violencia y/o violación sexual ocasionan lesiones físicas o enfermedades verificables a través de dichos exámenes».?

Sumado a ello, resulta relevante la postura adoptada por la Corte IDH en cuanto a la violencia sexual como acto discriminatorio. Al analizar el caso de Gladys Espinoza Gonzáles, el tribunal pudo determinar que los agentes estatales cometieron tales hechos a modo de estrategia contra el grupo subversivo al que se la vinculaba. Así, la Corte IDH concluyó que «el haber sometido a la señora Espinoza a dicha práctica generalizada constituye discriminación individualizada por su condición de mujer, en violación del artículo 1.1 de la Convención Americana en su perjuicio, en relación con los derechos a la integridad personal y a la honra y la dignidad». ${ }^{8}$

Por último, es necesario resaltar lo establecido en el caso Mujeres de Atenco, dada la estrecha relación de su plataforma fáctica con el tema del presente trabajo. Allí la Corte concluyó que

los agentes policiales instrumentalizaron los cuerpos de las mujeres detenidas como herramientas para transmitir su mensaje de represión y desaprobación de los medios de protesta empleados por los manifestantes. Cosificaron a las mujeres para humillar, atemorizar e intimidar las voces de disidencia a su potestad de mando. La violencia sexual fue utilizada como un arma más en la represión de la protesta, como si junto con los gases lacrimógenos y el equipo antimotín, constituyeran sencillamente una táctica adicional para alcanzar el propósito de dispersar la protesta y asegurarse de que no volviera a cuestionarse la autoridad del Estado. Este tipo de conductas en el mantenimiento del orden público, más que reprochable, es absolutamente inaceptable. ${ }^{9}$

\section{Protestas sociales y represión contra mujeres en Argentina, Chile y México}

En los últimos años, las movilizaciones feministas de América Latina se han ido retroalimentando entre ellas. Así, un sentimiento de sororidad y cooperación ha ido surgiendo entre las mujeres de los países latinoamericanos ante la sociedad patriarcal imperante. ${ }^{10}$ Ello se observa, por ejemplo, con la forma en la que distintos lemas,

7. Sentencia del caso Espinoza Gonzáles con Perú, foja 153.

8. Sentencia del caso Espinoza Gonzáles con Perú, foja 229.

9. Sentencia del caso Mujeres Víctimas de Tortura Sexual en Atenco con México, foja 204.

10. Las siguientes notas periodísticas son algunas de las que dan cuenta de esta realidad: «El feminismo marca el paso de la política de América Latina», El País, 4 de marzo de 2020, disponible en https:// 
como el \#NiUnaMenos, han sido reproducidos por los grupos activistas con el objetivo de unir fuerzas ante la discriminación y violencia que viven las mujeres en la región. ${ }^{11}$ Las manifestaciones han ido así haciéndose eco y logran permear la realidad cotidiana. Un claro ejemplo de ello pudo observarse durante los últimos 8 de marzo (conocido como $8 \mathrm{M}$ ) con los paros internacionales por el Día Internacional de la Mujer a los que se adhirieron grupos de mujeres de toda la región. ${ }^{12}$

Por desgracia, si bien estas movilizaciones son en su mayoría de carácter pacífico, tienen como respuesta represión por parte de la Policía y en algunos casos del Ejército. ${ }^{13}$ En Argentina, por ejemplo, en la manifestación por el 8M de 2017 las mujeres fueron reprimidas brutalmente por la Policía. Entre los testimonios recolectados se advierte que varias mujeres fueron detenidas por policías uniformados sin identificación y otros que iban vestidos de civil. Estos hechos ocurrieron incluso horas después de finalizada la marcha. A las mujeres las siguieron y las detuvieron mientras esperaban el colectivo o salían de algún lugar de comidas. La directora del área de justicia y seguridad del Centro de Estudios Legales y Sociales (CELS), Paula Litvachky, se refirió a estos hechos como una "cacería policial». ${ }^{14}$

En Chile, con las protestas por los derechos de las mujeres organizadas a partir

bit.ly/3qUOtnI; Cristina Armunia Berges, «El feminismo gana terreno en Argentina: cómo Ni Una Menos abrió paso a la despenalización del aborto", El Diario, 9 de marzo de 2018, disponible en https:// bit.ly/2UxiT3s; «Las manifestaciones por el 8M de Ciudad de México, Santiago de Chile y Madrid vistas desde el aire», El País, Verne, 9 de marzo de 2020, disponible en https://bit.ly/36liQdy; «Feminicidios y violencia contra las mujeres provoca el grito de \#NiUnaMenos», El Sol de México, 10 de marzo de 2020, disponible en https://bit.ly/36oZpRa.

11. Véase, por ejemplo, «NiUnaMenos: Diferentes países se acoplan al paro nacional de mujeres», Perfil, 19 de octubre de 2016, disponible en https://bit.ly/3jYzAiF.

12. Véase, por ejemplo: Lorena Panzerini, «Un nuevo 8 de marzo en la calle», Página 12, 8 de marzo de 2021, disponible en https://bit.ly/3dYgmpK; Laura Castellanos, «8M: El feminismo es el principal movimiento opositor en México», The Washington Post, 7 de marzo de 2021, disponible en https://wapo. st/3yGtSGe; Sally Palomino, Darinka Rodríguez, Naiara Galarraga Cortázar, Rocío Montes y Sara España, «Las mujeres de América Latina, en la calle o en las redes, claman contra la violencia machista», El País, 8 de marzo de 2021, disponible en https://bit.ly/3hNdLjD; «Con paro de labores y manifestaciones en las calles, exigen detener los feminicidios», Animal Político, 19 de octubre de 2016, disponible en https://bit.ly/3eoXGWt; «Se viene el paro», La Tinta, 6 de marzo de 2020, disponible en https://bit. ly/3k2KZOz.

13. La represión estatal como modo de operar se encuentra tan arraigada que, frente a la convocatoria para marchas, policías feministas en Argentina decidieron pronunciarse a favor de las manifestaciones por los derechos de las mujeres. Así, esta red de policías emitió un documento en el que se negaron a reprimir a las manifestantes. Véase, por ejemplo, «Impulsan una red de policías feministas: Piden no reprimir en las marchas de mujeres», LM Neuquén, 15 de febrero de 2019, disponible en https://bit. ly/3wmEXeg.

14. «Argentina: Represión al movimiento de mujeres en el \#8M», LATFEM, 10 de marzo de 2017, disponible en https://bit.ly/3xrUgUo. 
de octubre de 2019 hubo un número alarmante de casos de abuso de fuerza y detenciones ilegales, entre otros. ${ }^{15}$ Ante estas circunstancias, un grupo feminista presentó un recurso judicial para evitar casos de represión durante las marchas por el $8 \mathrm{M}$ de $2020 .{ }^{16} \mathrm{~A}$ pesar de ello, una vez más sus derechos fueron vulnerados a manos de los agentes estatales, al ser reprimidas por los carabineros en la protesta. ${ }^{17}$

Similares hechos se dieron también en México. Así, en septiembre de 2020, se llevó adelante una marcha de mujeres en Ciudad Juárez contra la violencia policial. Esta protesta se originó por hechos previos ocurridos en Guanajuato, donde policías habían reprimido a manifestantes que marchaban a causa de la denuncia de una adolescente contra un policía local que la había acosado sexualmente. ${ }^{18}$ La protesta de Ciudad Juárez también fue objeto de represión policial. ${ }^{19}$ Lo mismo sucedió en Ciudad de México, donde los policías presentes llegaron a cuadruplicar en número a las manifestantes. ${ }^{20}$

Aunque los varones son también objeto de represión, la violencia ejercida contra las mujeres suele poseer ciertas características diferenciadoras (Henderson, 2004: 1.032). La más típica es el carácter sexual de los actos violentos. Esto puede observarse a través de los testimonios de mujeres reprimidas durante y después de las manifestaciones: muchas de ellas fueron obligadas a desvestirse frente a los agentes estatales y les fueron negados elementos esenciales de higiene femenina, entre otros vejámenes. En casos aún más graves, las mujeres fueron abusadas sexualmente, hasta llegar incluso al extremo del femicidio.

Si bien este trabajo no desconoce que los varones también pueden ser víctimas de abuso sexual por parte de agentes estatales, sigue siendo oportuno hablar de este tipo de actos como elemento diferenciador de la represión contra las mujeres. En contraste con lo que sucede con los varones, la violencia sexual contra las mujeres responde a un patrón de conducta por parte del Estado que se enmarca en la estructura social de discriminación y subyugación a la que son sometidas aquellas (Saba, 2016). En este

15. «Informe anual 2019: Situación de los derechos humanos en Chile en el contexto de la crisis social», Instituto Nacional de Derechos Humanos, diciembre de 2019, disponible en https://bit.ly/3jWz8Sf.

16. «Feministas presentan recurso para evitar represión en marcha del 8M», El Día, 19 de febrero de 2020, disponible en https://bit.ly/3eniKvR.

17. Véase, por ejemplo, «8M en Chile: Marcha multitudinaria y represión de Carabineros en Santiago», Perfil, 8 de marzo de 2020, disponible en https://bit.ly/3kogJUG; «Denuncian represión contra movilización de mujeres en Chile», Telesur, 9 de marzo de 2020, disponible en https://bit.ly/2TUsVvg.

18. «Policías detienen a manifestantes y agreden periodistas en marcha de mujeres contra el acoso sexual en León», Animal Político, 23 de agosto de 2020, disponible en https://bit.ly/3hPjV2B.

19. Rocío Gallegos, «Marcha de mujeres en Ciudad Juárez contra la violencia policial culmina con represión», Animal Político, 6 de septiembre de 2020, disponible en https://bit.ly/3AIsIvM.

20. María Fernanda Navarro, «El fuerte operativo policial con el que el gobierno de CDMX rompió una marcha feminista», Forbes, 29 de septiembre de 2020, disponible en https://bit.ly/2VnNghz. 
contexto, debe tenerse en cuenta que el cuerpo de las mujeres ha sido históricamente considerado propiedad de los varones y, por ello, aunque la violencia sexual contra ambos géneros es repudiable, las causas que la originan son distintas (Irigaray, 1985; Pateman, 1995).

En Argentina, en la misma marcha por el 8M mencionada arriba, una de las mujeres detenidas fue obligada a desvestirse en dos ocasiones frente a los policías. ${ }^{21} \mathrm{~A}$ ello se le suman casos de amenazas de índole sexual y tocamientos, entre otros, por parte del personal de policía. En Chile, el Instituto Nacional de Derechos Humanos (INDH) recibió, a un mes del comienzo de las protestas, 96 querellas por torturas o tratos crueles, inhumanos o degradantes que incluían violencia sexual. Así, el INDH expuso en su informe anual que «la violencia sexual afectó en mayor medida a mujeres y niñas, pues del total de víctimas representadas por el INDH tres de cada diez mujeres denunciaron este tipo de delitos». ${ }^{22}$ Por su parte, en México, las manifestantes que marcharon en contra del abuso que se había perpetrado contra una adolescente en Guanajuato fueron a su vez abusadas sexualmente por los policías. ${ }^{23} \mathrm{Se}$ observa, entonces, que la represión contra las manifestantes suele incluir violencia de carácter sexual.

A pesar de ello, las mujeres han continuado con las marchas por sus derechos. En parte, esto se debe a que estos actos misóginos no son ajenos a su vida diaria. La violencia contra las mujeres responde a la estructura patriarcal en la que la sociedad tiene su engranaje, la cual avala y reproduce la discriminación contra ellas. A fin de cuentas, tanto el Estado como la sociedad ejercen actos de violencia contra las mujeres de forma periódica. Por ello, las manifestaciones por los derechos de las mujeres resultan esenciales contra esta política androcéntrica. Con ellas se visibiliza toda una historia de opresión, a través de la búsqueda del reconocimiento de sus derechos.

\section{El carácter diferenciador de la represión contra las mujeres}

Teniendo un panorama general de estos países de América Latina, resta comprender cuáles son las razones específicas que se encuentran detrás de la represión estatal contra las mujeres manifestantes. Existe vasta literatura académica que aborda las razones de ser de la represión estatal ante las protestas sociales (Combes y Fillieule, 2011). No obstante, como fue señalado en la introducción, es muy limitado el análisis sobre el carácter diferenciado que tiene este tipo de violencia institucional sobre las mujeres. Esto se debe, en general, a que la academia ha centrado su estudio en

\footnotetext{
21. LATFEM, «Argentina».

22. INDH, «Informe anual 2019».

23. «Marcha contra la violencia en Guanajuato termina con más abusos: Manifestante acusa agresión sexual por parte de policías», Infobae, 23 de agosto de 2020, disponible en https://bit.ly/3qYdONN.
} 
las experiencias de los varones por sobre las de las mujeres. Si bien uno de los argumentos que justifican este enfoque es que la mayor parte de las personas que son reprimidas son varones, esta postura niega la discriminación estructural existente contra las mujeres (Henderson, 2004). En efecto, estos números son consecuencia de la subrepresentación de las mujeres en la vida política, consecuencia del monopolio que históricamente han poseído sobre ella los varones. ${ }^{24}$

Esta subrepresentación responde a causas históricas estrictamente relacionadas con la mirada androcéntrica de la sociedad (Maffía, 2005). Como explica Carole Pateman (1995), al pacto expuesto por Jean-Jacques Rousseau le antecede un contrato sexual. Este pacto -ignorado por los teóricos clásicos en sus escritos- fue el que ubicó a los varones como individuos superiores a las mujeres. Así, si bien el pacto social lleva el estandarte de la igualdad como bandera, es concebida solo entre varones, toda vez que, para que pudiera alcanzarse, debieron someter primero a las mujeres bajo su dominio. Las mujeres son entonces consideradas como ciudadanas de segunda, hallándose bajo el control de los varones que ocupan los lugares de mayor jerarquía social (Beauvoir, 2016). ${ }^{25}$

Entre las diversas consecuencias del contrato sexual, una de las más notorias es haber dado lugar al fenómeno conocido como división sexual del trabajo (Kergoat, 2003). De acuerdo con este concepto, las mujeres se encuentran confinadas al ámbito privado a cargo de las tareas reproductivas (Rodríguez Enríquez y Marzonetto, 2015); mientras tanto, los varones lideran el espacio público que posee mayor valor social agregado (Kergoat, 2003). Esto otorga a los varones el control no solo sobre las tareas productivas, sino también de las que llevan a cabo las mujeres. Así, el rol que ocupan los varones en la sociedad es considerado de mayor importancia que el de las mujeres, con lo que las tareas reproductivas quedan invisibilizadas a pesar de su importancia como generadoras de la fuerza de trabajo (Pautassi, 2007).

Entre las labores productivas que históricamente han desarrollado los varones se encuentran, justamente, las relacionadas con la política. Autoras como Conway Henderson (2005) afirman que el monopolio del espacio político por los varones constituye, en materia de género, una de las desigualdades más llamativas. En mismo sentido, órganos de derechos humanos como el Comité de la Convención para eliminar todas las formas de discriminación contra la mujer (CEDAW, por sus siglas en inglés) se han pronunciado al respecto. El Comité de la CEDAW ha advertido, con notoria preocupación, la ausencia de mujeres en los espacios de toma de decisiones políticas y su exclusión de los cargos de representación ciudadana. Debido a ello, el órgano de

24. «Recomendación general 25, párrafo 1 del artículo 4 de la Convención sobre la eliminación de todas las formas de discriminación contra la mujer: Medidas especiales de carácter temporal», Comité para la Eliminación de la Discriminación contra la Mujer, 2004, disponible en https://bit.ly/2UxzLHk.

25. CEDAW, «Recomendación general 25...». 
control ha requerido a los Estados que adopten medidas que permitan a las mujeres disfrutar de sus derechos políticos en igual medida que los varones. ${ }^{26}$

Si bien es cierto que en los últimos años, gracias a iniciativas tanto locales como regionales, las mujeres han ido adquiriendo mayor representación política, los backlashes (contragolpes) no han sido menores (Krook y Restrepo, 2016: 141). En un trabajo sobre violencia política en América Latina, Mona Lena Krook y Juliana Restrepo Sanín exponen cómo las mujeres son violentadas con el objetivo de negar sus derechos políticos. Debido a ello, las autoras caracterizan a la violencia en política como un «delito mensaje» (Krook y Restrepo, 2016: 140). Además, estos actos tienen la consecuencia de generar una mayor percepción de vulnerabilidad por las demás mujeres.

El hecho de que en el marco político las mujeres sean violentadas sexualmente dista de ser un dato menor. Las autoras explican que «la sexualidad de las mujeres es un símbolo potente. Las amenazas de violación se aprovechan de las creencias de que las mujeres son vulnerables y que pueden ser castigadas usando acciones de índole sexual» (Krook y Restrepo, 2016: 142). Estos actos tienen por propósito "poner en su lugar» a las mujeres que intentan incorporarse en el ámbito político, al considerarse parte del dominio masculino. De este modo, «los cuerpos de las mujeres, conectados con sus roles sociales estereotipados, se convierten en foco central de esta violencia» (Krook y Restrepo, 2016: 140).

Adentrándonos ahora en el ámbito de las protestas sociales, resulta necesario destacar el estudio elaborado por Henderson, «The political repression of women». $\mathrm{Si}$ bien este trabajo es de comienzos de siglo, deviene importante dado que ilustra las dinámicas específicas de la represión contra las mujeres durante las manifestaciones. Así las cosas, Henderson (2004: 1.030) plantea al inicio de su investigación dos posibles explicaciones: i) el empoderamiento de las mujeres - si las mujeres se empoderan, generan un obstáculo a las autoridades gubernamentales, quienes, en consecuencia, responden con represión-; y ii) la vulnerabilidad de las mujeres.

La primera idea surge a partir de ciertos estudios que hacen referencia a la repressive propensity (propensión a la represión) de los Gobiernos cuando consideran que ciertos actos de conducta pueden ser amenazantes. Esta noción es aplicable, en general, de forma lineal: a mayor amenaza, mayor represión (Henderson, 2004: 1.034). Esta explicación partiría de la idea según la cual, ante el empoderamiento de las mujeres (tanto política como socioeconómica), estas desafiarían a los Gobiernos controlados por varones. Entonces, de acuerdo con este postulado, los Estados reprimirían a las mujeres por esta sensación de amenaza.

La segunda explicación tiene como punto de partida la desigualdad socioeco-

26. «Recomendación general 23, vida política y pública», Comité para la Eliminación de la Discriminación contra la Mujer, 1997, disponible en https://bit.ly/3B6hQs3. 
nómica y política entre varones y mujeres. Con base en ello, se entiende que las mujeres se encuentran en una situación de vulnerabilidad que los varones perpetúan o intensifican a través de la represión. Así se procura mantener a las mujeres en un rol de subordinación. A diferencia de la primera postura, aquí no se requiere que exista un sentimiento de amenaza por parte del Gobierno. Por el contrario, la represión contra las mujeres se aplica como un mensaje: «Stay in your place or expect to be hurt» («quédate en tu lugar o espera ser lastimada») es la expresión que utiliza Henderson (2004: 1.035) para ilustrar esta idea. Por lo tanto, mientras en el caso anterior son las mujeres las que acorralan al Gobierno, aquí es el Estado el que las asedia mediante represión.

Luego de desarrollar su estudio empírico, Henderson llega a la respuesta de esta disyuntiva: la represión contra las mujeres no se debe a su empoderamiento. Muy por el contrario, cuando las mujeres se empoderan, el Gobierno se ve desinteresado en hacer uso de dichos mecanismos. La represión, por tanto, entra en escena cuando las autoridades toman provecho de la situación de vulnerabilidad socioeconómica y política de las mujeres (Henderson, 2004: 1.044). Entonces, de acuerdo con este estudio, el empoderamiento de las mujeres se constituye en un modo de repeler la represión.

Por desgracia, este empoderamiento no necesariamente implica una disminución de la violencia en otros ámbitos (como el doméstico). En efecto, los actos violentos contra las mujeres en la esfera privada se generan como consecuencia de un microcontexto en que el varón se siente superior jerárquicamente (Henderson, 2004: 1.040). Entonces, cuando este siente que su privilegio se encuentra en peligro, recurre a la violencia como recurso. En cambio, la represión se enmarca en un macrocontexto en que se adoptan decisiones que apelan a la violencia para intimidar, no para resguardar los privilegios individuales de los varones que perpetúan la violencia (Henderson, 2004: 1.040).

\section{Conclusiones}

Como puede observarse a través de estas páginas, el derecho a la protesta social es esencial en el marco de un Estado de derecho. Así las cosas, los países latinoamericanos que forman parte del sistema interamericano de derechos humanos deben cumplir con los estándares ya mencionados. En particular, el uso de la fuerza por los Estados debe ser una medida de ultima ratio, sobre todo si nos estamos refiriendo a un grupo estructuralmente discriminado como lo son las mujeres. Con base en esto, puede asegurarse sin mayores miramientos que el fenómeno de represión es incompatible con el derecho sub examine. Este postulado responde al hecho de que la represión contra las protestas lideradas por mujeres dista de cumplir con los requisitos para que el uso de la fuerza sea legítimo.

A pesar de ello, estos actos de violencia se encuentran tan arraigados en las socie- 
dades latinoamericanas que suelen naturalizarse. A su vez, la falsa neutralidad con la que es analizado este fenómeno resulta alarmante. Si bien existen puntos en común entre los actos de violencia policial contra varones y mujeres, estas sufren tipos de violencia institucional de manera diferenciada. Un ejemplo claro de este elemento diferenciador es la violencia sexual. Así se observa en los países de América Latina bajo análisis, donde las manifestantes suelen ser objeto de represión de índole sexual tanto durante como después de las protestas, como ilustran las experiencias de la región.

Esta violencia responde en gran medida a la segregación de las mujeres del ámbito político (el cual se ha encontrado históricamente bajo el monopolio de los varones). De este modo, siguiendo el estudio de Henderson, se puede afirmar que - en general- la represión diferenciada contra las mujeres se aplica a modo de mensaje, para intentar «regresarlas» al lugar que, de acuerdo con el contrato sexual y la división sexual del trabajo, pertenecen. El Estado, entonces, aprovecha la situación de desventaja en la que se hallan las mujeres por las desigualdades socioeconómicas y políticas para limitarlas en sus reclamos. Así lo entendió también la Corte IDH en Mujeres de Atenco.

A modo de cierre, resulta importante prestar atención a la unión entre mujeres que se está generando en América Latina. Las barreras geográficas se han desdibujado y las causas se han ido transmitiendo y haciendo una en toda la región. Esta sororidad y cooperación hacen que, a pesar de la represión estatal, cada vez más mujeres salgan a la calle. Así lo relatan las manifestantes argentinas que, mientras eran detenidas ilegalmente el $8 \mathrm{M}$ de 2017 , escuchaban cómo grupos de mujeres gritaban sus nombres fuera de las comisarías reclamando que las liberaran.

\section{Referencias}

Beauvoir, Simone de (2016). El segundo sexo. Buenos Aires: Debolsillo.

CELS, Centro de Estudios Legales y Sociales (2016). Los Estados latinoamericanos frente a la protesta social. Buenos Aires.

CIDH, Comisión Interamericana de Derechos Humanos (2019). Protesta y derechos humanos. OEA/Ser.L/V/II, CIDH/RELE/INF.22/19. Washington D.C. Disponible en https://bit.ly/3wvvoLs.

Combes, Hèlene y Olivier Fillieule (2011). «Repression and protest structural models and strategic interactions». Revue Française de Science Politique (edición en inglés), 61 (6): 1-24. DOI: 10.3917/rfsp.616.1047.

Henderson, Conway W. (2004). «The political repression of women». Human Rights Quarterly, 26 (4): 1.028-1.049. DOI: 10.1353/hrq.2004.0044.

IrIgARAY, Luce (1985). The sex which is not one. Ithaca: Cornell University Press.

Kergoat, Danièle (2003). «De la relación social de sexo al sujeto sexuado». Revista Mexicana de Sociología, 65 (4): 841-861. DOI: 10.2307/3541585. 
KrooK, Mona Lena y Juliana Restrepo Sanín (2016). «Género y violencia política en América latina. Conceptos, debates y soluciones». Política y Gobierno XXIII, 23 (1): 127-162. Disponible en https://bit.ly/3elZvxn.

Maffía, Diana (2005). «El contrato moral». En Elisa Carrió y Diana Maffía (editoras), Búsquedas de sentido para una nueva política. Buenos Aires: Paidós.

Pateman, Carol (1995). El contrato sexual. Barcelona: Anthropos.

PAUtAssi, Laura C. (2007). ¡Cuánto trabajo mujer! El género y las relaciones laborales. Buenos Aires: Capital Intelectual.

Rodríguez EnRíQuez, Corina y Gabriela Marzonetto (2015). «Organización social del cuidado y desigualdad: El déficit de políticas públicas de cuidado en Argentina». Perspectivas de Políticas Públicas, 8: 103-134. DOI: 10.18294/rppp.2015.949.

SABA, Roberto (2016). Más allá de la igualdad formal ante la ley: ¿Qué les debe el Estado a los grupos desaventajados? Buenos Aires: Siglo XXI.

Waldmann, Peter (1995). «Represión estatal y paraestatal en Latinoamérica». América Latina Hoy, 10: 21-28. Disponible en https://bit.ly/36nP2Nt.

\section{Sobre las autoras}

Mariana Brocca es becaria doctoral del Consejo Nacional de Investigaciones Científicas y Tecnológicas (Conicet) y doctoranda por la Facultad de Derecho de la Universidad de Buenos Aires, Argentina. Máster en Derecho Internacional de los Derechos Humanos por la Universidad de Notre Dame, Estados Unidos (honores summa cum laude). Abogada y docente por la Universidad Nacional del Centro de la Provincia de Buenos Aires, Argentina. Su correo electrónico es mariana.brocca@ azul.der.unicen.edu.ar. (D) https://orcid.org/0000-0002-7525-9098.

Camila Agustina Ormar es doctoranda por la Facultad de Derecho de la Universidad de Buenos Aires. Abogada egresada con honores y docente de la Facultad de Derecho de la Universidad Nacional del Centro de la Provincia de Buenos Aires. Su correo electrónico es camila.ormar@azul.der.unicen.edu.ar. (D) https://orcid. org/0000-0002-7073-0637. 
El Anuario de Derechos Humanos es una publicación semestral de referencia y consulta en materia de derechos humanos y campos afines. Busca ser un espacio de discusión de los temas centrales en el ámbito nacional e internacional sobre derechos humanos. Es publicado desde 2005 por el Centro de Derechos Humanos de la Facultad de Derecho de la Universidad de Chile.

\author{
EDITORA \\ Claudia Iriarte Rivas \\ ciriarter@derecho.uchile.cl \\ SITIO WEB \\ anuariocdh.uchile.cl \\ CORREO ELECTRÓNICO \\ anuario-cdh@derecho.uchile.cl \\ LICENCIA DE ESTE ARTÍCULO \\ Creative Commons Atribución Compartir Igual 4.o Internacional
}

\author{
\% \\ La edición de textos, el diseño editorial \\ y la conversión a formatos electrónicos de este artículo \\ estuvieron a cargo de Tipográfica \\ (www.tipografica.io)
}

